\title{
Probiotics (Bifidobacterium longum) Increase Bone Mass Density and Upregulate Sparc and Bmp-2 Genes in Rats with Bone Loss Resulting from Ovariectomy
}

\author{
Kolsoom Parvaneh, ${ }^{1}$ Mahdi Ebrahimi, ${ }^{2}$ Mohd Redzwan Sabran, \\ Golgis Karimi, ${ }^{1}$ Angela Ng Min Hwei, ${ }^{3}$ Saif Abdul-Majeed, ${ }^{4}$ Zuraini Ahmad, \\ Zuriati Ibrahim, ${ }^{1}$ and Rosita Jamaluddin ${ }^{1}$ \\ ${ }^{1}$ Department of Nutrition and Dietetics, Faculty of Medicine and Health Sciences, Universiti Putra Malaysia, 43400 Serdang, \\ Selangor, Malaysia \\ ${ }^{2}$ Department of Veterinary Preclinical Sciences, Faculty of Veterinary Medicine, Universiti Putra Malaysia, 43400 Serdang, \\ Selangor, Malaysia \\ ${ }^{3}$ Tissue Engineering Center, Faculty of Medicine, Universiti Kebangsaan Malaysia, 50300 Kuala Lumpur, Malaysia \\ ${ }^{4}$ Department of Life Sciences, School of Pharmacy, International Medical University, No. 126, Jalan Jalil Perkasa 19, Bukit Jalil, \\ 57000 Kuala Lumpur, Malaysia \\ ${ }^{5}$ Department of Biomedical Science, Faculty of Medicine and Health Sciences, Universiti Putra Malaysia, 43400 Serdang, \\ Selangor, Malaysia
}

Correspondence should be addressed to Rosita Jamaluddin; rositaj@upm.edu.my

Received 19 May 2015; Revised 10 July 2015; Accepted 14 July 2015

Academic Editor: Esmaiel Jabbari

Copyright (C) 2015 Kolsoom Parvaneh et al. This is an open access article distributed under the Creative Commons Attribution License, which permits unrestricted use, distribution, and reproduction in any medium, provided the original work is properly cited.

Probiotics are live microorganisms that exert beneficial effects on the host, when administered in adequate amounts. Mostly, probiotics affect the gastrointestinal (GI) tract of the host and alter the composition of gut microbiota. Nowadays, the incidence of hip fractures due to osteoporosis is increasing worldwide. Ovariectomized (OVX) rats have fragile bone due to estrogen deficiency and mimic the menopausal conditions in women. Therefore, this study aimed to examine the effects of Bifidobacterium longum (B. longum) on bone mass density (BMD), bone mineral content (BMC), bone remodeling, bone structure, and gene expression in OVX rats. The rats were randomly assigned into 3 groups (sham, OVX, and the OVX group supplemented with $1 \mathrm{~mL}$ of $B$. longum $10^{8}-10^{9}$ colony forming units $\left.(\mathrm{CFU}) / \mathrm{mL}\right)$. B. longum was given once daily for 16 weeks, starting from 2 weeks after the surgery. The B. longum supplementation increased $(p<0.05)$ serum osteocalcin $(\mathrm{OC})$ and osteoblasts, bone formation parameters, and decreased serum C-terminal telopeptide (CTX) and osteoclasts, bone resorption parameters. It also altered the microstructure of the femur. Consequently, it increased BMD by increasing $(p<0.05)$ the expression of Sparc and Bmp-2 genes. B. longum alleviated bone loss in OVX rats and enhanced BMD by decreasing bone resorption and increasing bone formation.

\section{Introduction}

Osteoporosis is a bone metabolic disorder, which is explained by low bone mass and deterioration of the bone tissue, leading to increase in bone weakness. Due to osteoporosis, bone density and microarchitecture of the bone tissue are decreased, leading to the risk of fracture [1]. The incidence of hip fractures due to osteoporosis is increasing worldwide and the elderly population is mostly affected by the risk of fracture [2]. The total disability adjusted life years were reported at 5.8 million worldwide. Fifty-one percent of this number was a result of fractures, which occurred mostly in population from Europe and America. Thus, osteoporotic fractures were reported as an important cause of mortality 
and morbidity specifically in developed countries [3]. Indeed, the most common type of osteoporosis is associated with postmenopausal conditions among women aged 50 years and over [4].

One-third of women lifespan is spent during the menopausal period [5]. Thus, it is necessary to reduce the adverse effect of menopause on women health. Hormone replacement therapy (HRT) was shown to reduce the risk of fracture among patients with osteoporosis. However, due to its daily injection, most women are not keen on this treatment. Moreover, HRT increases the possibility of tumorigenesis [6]. Therefore, the identification of alternative ways to increase bone formation and maintain the bone strength is considered vital, especially for menopausal women.

A possible osteoporosis treatment is the consumption of probiotics [7, 8]. Probiotics are live microorganisms [9], sometimes derived from fermented food [10], which confer a beneficial physiological effect on the host when administered in adequate amounts $[9,11]$. Recently, few studies reported that probiotics can decrease the incidence of osteoporosis $[8,12,13]$. Some strains of probiotics are investigated for their effects on osteoporosis such as Lactobacillus casei, Lactobacillus plantarum, Lactobacillus paracasei, and Bifidobacterium longum (B. longum).

Recently, the important function of gut microbiota (GM) in the treatment of different diseases, including bone loss, was studied. The GM comprises millions of bacteria and can be modulated with some environmental factors such as diet. The absence of GM in germ-free mice increased bone loss. However, colonization of the germ-free mice with a normal GM increased immunity and bone mass [14]. Probiotics mostly act by changing the composition of the GM [15] and increase the solubility and absorption of minerals, which lead to the modulation of the immune system $[16,17]$. The bone remodeling process is one system modulated by probiotics [12].

The regulation of bone metabolism is complex and some factors such as genetics, the environment, and lifestyle contribute to the bone metabolism [18]. In addition, genetic factors play a vital role in bone turnover, which have accounted for 70 to $80 \%$ of variation in bone density [19]. The cells that influence bone density are osteoblasts, osteoclasts, osteocytes, and lining cells with their own structure and role. These cells are mainly affected by probiotics during the bone remodeling process [1]. Osteoclasts are large, multinucleated cells associated with osteoclastogenesis and are responsible for bone resorption. Osteoblasts are mononuclear bone formation cells and are responsible for the bone formation and mineralization. Osteoid is located on the bone surface and plays a role in the mechanical stimulation and initiation of the remodeling response [20].

Ovariectomy in rats causes bone loss [21]. OVX is defined as the surgical removal of one or both ovaries. This term is usually used in basic science studies to explain the removal of ovaries in laboratory animals, including rodents. OVX leads to the loss of ability to secrete estrogen and progesterone. Besides, the surgery also decreases testosterone production and leads to a condition known as surgical menopause. Thus, with the OVX surgical process, sexual hormones are
TABLE 1: Nutrients composition of rat chow diet.

\begin{tabular}{lc}
\hline Standard rat chow diet ingredient & \\
\hline Crude protein & $21.0 \%$ \\
Crude fiber & $7.3 \%$ \\
Crude fat & $3.0 \%$ \\
Moisture & $13.0 \%$ \\
Ash & $8.0 \%$ \\
Calcium & $1.0 \%$ \\
Phosphorus & $0.5 \%$ \\
Nitrogen-free extract & $49.0 \%$ \\
\hline
\end{tabular}

decreased, followed by a rise in bone loss and the risk of bone fractures, which are similar to menopausal osteoporotic conditions in women.

To the best of our knowledge, no study has been conducted and published on the effect of B. longum in OVX rats. Therefore, the aim of this study was to examine the effectiveness of the probiotic, B. longum, in protecting rats from OVX-induced bone loss. Additionally, this study evaluated the expression of a set of key genes related to bone metabolism.

\section{Materials and Methods}

2.1. Animal Model and Food Intake. Twenty-four 10-weekold female mature Sprague-Dawley rats, with a mean weight of 280-290 g, were obtained from the Faculty of Medicine and Health Sciences, Universiti Putra Malaysia (Serdang, Selangor, Malaysia). The rats were placed in plastic cages in a controlled environment animal facility at $22 \pm 2^{\circ} \mathrm{C}$ with a 12-hour light/dark cycle. They were acclimatized for two weeks and given a standard rat chow pellet (Ridley Agri Products, Sydney, New South Wales, Australia) (Table 1) and ad libitum water access. The animal study was performed in an animal house at the Faculty of Medicine and Health Sciences, Universiti Putra Malaysia. Guidelines for the use of animals were strictly followed. The study was approved by the Animal Care and Use Committee (ACUC) of the Faculty of Medicine and Health Sciences, Universiti Putra Malaysia, with approval number UPM/FPSK/PADS/BR-UUH/00483.

2.2. Surgical Procedure and Grouping. The rats were weighed with a digital weighing scale (Marte-AS 2000C, Sao Paulo, Brazil) and, prior to the surgery, the body weight-matched rats were randomly divided into 3 groups with 8 rats in each group, namely, G1: sham-ovariectomized (sham), G2: ovariectomized (OVX), and G3: OVX + Bifidobacterium longum (OVX + B. longum). Either sham-OVX or OVX surgery was then performed on specific groups. Body weight was determined once a week. Before surgery, the rats were anesthetized using a combination of xylazine and ketamine $12 \mathrm{mg} / 80 \mathrm{mg} / \mathrm{kg}$, injected intraperitoneally [22]. The same surgeon did all surgery procedures.

2.3. Probiotic Supplementation. After surgery, the rats were placed back in their cage for 2 weeks to recover. The rats 
in group 3 were then supplemented with $1 \mathrm{~mL}$ of $B$. longum $\left(10^{8}-10^{9}\right)(\mathrm{CFU} / \mathrm{mL})$, via oral gavage daily throughout the study (16 weeks), while sham and control groups received demineralized water daily. The amount of the bacteria used was based on a previous study [7]. The B. longum bacteria were purchased from the American Type Culture Collection (ATCC 15707; Rockville, MD, USA) and were activated at three continuous times in MRS broth (De Man Rogosa and Sharpe, Difco, Detroit, MI, USA) modified with $0.02 \%$ sodium carbonate, $0.01 \%$ calcium chloride dehydrate, and $1 \%$ solution of $0.05 \%$ L-cysteine as previously described [7].

2.4. Blood Biochemical Assay, Euthanasia, and Sampling. At the end of the intervention, the rats were anesthetized using a combination of xylazine and ketamine. The blood was collected via heart puncture and the animals were subsequently euthanized. The blood was placed into plain tubes and then centrifuged at $3,000 \mathrm{rpm}$ for $10 \mathrm{~min}$ at $4^{\circ} \mathrm{C}$, to obtain the serum for further analysis. The serum content of calcium and magnesium was measured using Roche Cobas C-311 Japan analyzer (Hitachi, Japan). OC and CTX were analyzed using standard commercial ELISA kit, Rat-MID OC EIA (IDS, Fareham, UK) for OC and RatLaps EIA (IDS) for CTX. The femurs were removed gently and preserved in $10 \%$ buffered formalin for further analyses. For RNA isolation purpose, the right femur was immediately transferred into RCL2 (Alpheys, Plaisir, France) and stored at $-80^{\circ} \mathrm{C}$ until further assessment.

2.5. Evaluation of the Bone Mineral Content. Calcium, magnesium, and zinc content of the femur were determined by atomic absorption spectrophotometry (novAA 400; Analytik Jena, Jena, Germany) according to a previously described procedure [23] with slight modifications. Firstly, the femurs were dried at $105^{\circ} \mathrm{C}$ for $24 \mathrm{~h}$ and then placed in a muffle furnace at $550^{\circ} \mathrm{C}$ for another $24 \mathrm{~h}$ to obtain the ash samples. The ashes were then crushed and hydrolyzed with $6 \mathrm{M}$ HCL. Calcium content was determined at a wavelength of $422.7 \mathrm{~nm}$ and lamp current $4.0 \mathrm{~mA}$, zinc content was determined at a wavelength of $213.9 \mathrm{~nm}$ and lamp current $2.0 \mathrm{~mA}$, and magnesium was determined at a wavelength of $285.2 \mathrm{~nm}$ and lamp current $2.0 \mathrm{~mA}$.

2.6. Micro-CT ( $\mu$-CT) Analysis. Femur images of each rat were acquired after dissection using $\mu$-CT (SkyScan, 1176, Brukler-Micro CT, Kontich, Belgium) at a resolution of $35 \mu \mathrm{m}$, filter 0.5 , exposure 100 , voltage 40 , and current 100. The correction of beam-hardening was performed to improve the quality of the image before scanning and during reconstruction. The femur images were then reconstructed with NRecon software version 1.6.3.3 and analyzed using SkyScan CT analyzer software version 1.9.1 to measure BMD $\left(\mathrm{gr} / \mathrm{cm}^{3}\right)$, the percentage of bone volume/total volume (BV/TV\%), trabecular thickness (Tb.Th) (mm), trabecular number (Tb.N) $\left(\mathrm{mm}^{-1}\right)$, trabecular separation (Tb.Sp) (mm), and the percentage of total porosity (to. pro\%). Calibration of the $\mu$-CT analyzer was performed with phantom material of calcium hydroxyapatite (CaHA) with a size of $4 \mathrm{~mm}$ in pairs, concentrations of 0.25 and $0.75 \mathrm{~g} / \mathrm{cm}^{3}$, and their attenuation coefficient (AC).
2.7. Evaluation of the Femur Physical and Biomechanical Properties. The femur weight was measured using a digital electronic scale (Marte-AS 2000C, Sao Paulo, Brazil). The distance from the top edge of the head to the bottom edge as the femur length and the circumference of the midpoint length as the femur thickness were measured using a stainless-steel caliper. The femoral breaking force was assessed by using the three-point bending method according to Goda et al. [24] in the center of the femur using a universal testing machine (Instron Ltd., 8874, High Wycombe, UK), equipped with $5 \mathrm{KN}$ load transducer.

2.8. Bone Histology Assessment. The formalin, in which the femurs were fixed, was periodically replaced until histology measurements were conducted. The first half of each left femur sample was allowed to decalcify in 5\% nitric acid over $24 \mathrm{~h}$. The samples were then transferred to an automated vacuum tissue processor (Leica ASP 300, Wetzlar, Germany) for dehydration. Samples were then embedded in paraffin histology wax and sectioned at $6 \mu \mathrm{m}$ thickness using a microtome (Leica, Wetzlar, Germany). At the final stage, the sectioned samples were stained with hematoxylin and eosin (H\&E) and observed under a light microscope (Olympus BX51TRFCCD Microscope, Tokyo, Japan). Static parameters, including osteoblast surface/bone surface (ObS/BS), osteoclast surface/bone surface (OcS/BS), eroded surface/bone surface (ES/BS), osteoid surface/bone surface (OS/BS), and osteoid volume/bone volume $(\mathrm{OV} / \mathrm{BV})$, were measured using a quantitative stereological method for histology, known as the Weibel technique [25]. All histomorphometric measurements were performed in the secondary spongy area, which is rich in trabecular. The selected region was located $1 \mathrm{~mm}$ from the lateral cortex and 3-7 $\mathrm{mm}$ from the lowest point of the growth plate [26]. Bone histomorphometric measurement was analyzed as recommended by the American Society of Bone Mineral Research (ASBMR) Histomorphometry Nomenclature Committee [26].

2.9. RNA Isolation and Real-Time PCR. RNA was extracted from the frozen right femur of the rats using the HiYield Total RNA Mini Kit (Real Biotech, Taipei, Taiwan) according to the manufacturer's instructions. RNA yield was then reported according to the absorbance at $260 \mathrm{~nm}$ using a NanoDrop ND-1000 UV-Vis (NanoDrop Technologies, Wilmington, DE, USA). The RNA quality was assessed by using the absorbance ratio at $260 / 280 \mathrm{~nm}$ along with the absorbance ratio of $260 / 230 \mathrm{~nm}$. The extracted RNA was utilized only when the absorbance ratio at A260/230 and A260/280 showed readings between 1.8 and 2.0 with specific bands on gel electrophoresis [27]. Next, RNA was reverse transcribed to cDNA using i-script cDNA synthesis kit (BioRad, Munich, Germany) according to the manufacturer's instruction. Real-time RT-PCR was performed in a reaction mixture containing $3 \mu \mathrm{L}$ of cDNA in a total volume of $25 \mu \mathrm{L}$ per reaction with the $2 \mathrm{x}$ SYBR Green I Hot-Start real-time PCR-Mix. Amplifications were then run in a Thermal Cycler using Eppendorf Realplex system (Eppendorf, Hamburg, Germany) with an initial denaturation at $95^{\circ} \mathrm{C}$ for $15 \mathrm{~min}$, followed by 40 cycles of $95^{\circ} \mathrm{C}$ for $15 \mathrm{~s}, 58.6^{\circ} \mathrm{C}$ for $40 \mathrm{~s}$, and 
TABLE 2: Effect of B. longum on blood serum parameters.

\begin{tabular}{|c|c|c|c|c|}
\hline Serum parameters & Sham & OVX & OVX + B. longum & $p$ value \\
\hline $\mathrm{OC}(\mathrm{ng} / \mathrm{mL})$ & $184.61 \pm 6.93^{\mathrm{a}}$ & $76.81 \pm 6.44^{\mathrm{c}}$ & $101.31 \pm 9.21^{\mathrm{b}}$ & 0.001 \\
\hline CTX (ng/mL) & $113.77 \pm 20.02^{\mathrm{b}}$ & $249.28 \pm 7.57^{\mathrm{a}}$ & $147.05 \pm 6.25^{\mathrm{b}}$ & 0.009 \\
\hline $\mathrm{Ca}(\mathrm{mmol} / \mathrm{L})$ & $2.27 \pm 0.12$ & $2.23 \pm 0.12$ & $2.27 \pm 0.06$ & 0.939 \\
\hline $\mathrm{Mg}(\mathrm{mmol} / \mathrm{L})$ & $0.97 \pm 0.07$ & $0.89 \pm 0.09$ & $0.91 \pm 0.06$ & 0.751 \\
\hline
\end{tabular}

Ten-week-old female Sprague-Dawley rats were supplemented with $1 \mathrm{~mL}$ of $B$. longum $\left(10^{8}-10^{9} \mathrm{CFU}\right)$ once a day for 16 weeks, starting 2 weeks after surgery, while sham and OVX groups received $1 \mathrm{~mL}$ of demineralized water. At the end of the study, the blood serum of the rats was analyzed for osteocalcin (OC), C-terminal telopeptide (CTX), calcium (Ca), and magnesium (Mg). Values represent the mean \pm standard error of the mean (SEM) $(n=8$ in each group).

${ }^{\mathrm{abc}}$ Values with different letters in the same row are significantly different at $p<0.05$ based on one-way ANOVA, followed by Tukey's post hoc test.

TABLE 3: Effect of B. longum on the mineral content of the femur.

\begin{tabular}{lccc}
\hline Femur mineral content $(\mathrm{mg} / \mathrm{g})$ & Sham & OVX & OVX $+B$. longum \\
\hline $\mathrm{Ca}$ & $246.23 \pm 10.14$ & $242.09 \pm 5.16$ & $242.45 \pm 15.26$ \\
$\mathrm{Mg}$ & $33.23 \pm 0.15$ & $32.44 \pm 0.12$ & $32.76 \pm 0.31$ \\
$\mathrm{Zn}$ & $17.23 \pm 2.04$ & $13.89 \pm 0.67$ & $13.96 \pm 1.25$ \\
\hline
\end{tabular}

Ten-week-old female Sprague-Dawley rats were supplemented with $1 \mathrm{~mL}$ of $B$. longum $\left(10^{8}-10^{9} \mathrm{CFU}\right)$ once a day for 16 weeks, starting 2 weeks after surgery, while sham and OVX groups received $1 \mathrm{~mL}$ of demineralized water. At the end of the study, the calcium $(\mathrm{Ca})$, magnesium $(\mathrm{Mg})$, and zinc $(\mathrm{Zn})$ content of the femur was analyzed. Values represent the mean $\pm \operatorname{SEM}(n=8$ in each group).

No significant difference was observed between the groups based on one-way ANOVA, followed by Tukey's post hoc test.

$68^{\circ} \mathrm{C}$ for $20 \mathrm{~s}$. Data were reported as fold changes relative to the housekeeping gene.

The forward and reverse primers were designed based on sequences obtained from the ENA and GenBank (http:// www.ncbi.nlm.nih.gov/tools/primer-blast/) databases as follows: Bmp-2, accession number NM_017178, forward primer: CAGGTCTTTGCACCAAGATG, and reverse primer: GCTGGACTTAAGACGCTTCC; Sparc, accession number NM_012656, forward primer: CAGGTGGAAATGGGAGAGTT, and reverse primer: GTTTGCAATGATGGTTCTGG; and glyceraldehyde-3-phosphate dehydrogenase $(\mathrm{GADPH})$ as a housekeeping gene, accession number NM_017008, forward primer: TCAAGAAGGTGGTGAAGCAG, and reverse primer: AGGTGGAAGAATGGGAGTTG. The primers were supplied by Helix Biotech (Helix Biotech Ltd., Richmond, British Columbia, Canada). The primers were then diluted to a final concentration of $100 \mu \mathrm{L}$ with nuclease-free water.

2.10. Enumeration of Bifidobacteria in the Feces. After probiotic supplementation, the fresh feces of the rats were cultivated in Bifidus Selective Medium agar (BSM agar, Fluka, Buchs, Switzerland) and bifidobacteria were enumerated after incubation. The plates of cultivated bacteria were placed for $72 \mathrm{~h}$ at $37^{\circ} \mathrm{C}$ in an anaerobic jar to provide anaerobic conditions by gas pack (Oxoid Ltd., Basingstoke, UK). After the incubation period, the colonies were counted using the colony-counting device (Stuart Scientific, Staffordshire, UK) and the number of colonies was expressed as $\log _{10} \mathrm{CFU} / \mathrm{g}$.

2.11. Statistical Analysis. The data were checked for normality using the UNIVARIATE procedure of SAS software (version 8.2, SAS Institute Inc., Cary, NC, USA). Microbial data were converted to $\log _{10}$ and reported as a wet weight basis. Data were analyzed by one-way analysis of variance (ANOVA) with PROC MIXED in SAS. The results were expressed as mean \pm SEM and the differences among the groups were analyzed with a post hoc Tukey's test. Significance was considered at $p<0.05$.

\section{Results}

3.1. The Effect of B. longum on Body Weight. At the end of the study, the body weight of the rats from the sham, OVX, and B. longum-fed groups was $349.5 \pm 29.1 \mathrm{~g}, 385.1 \pm 28.5 \mathrm{~g}$, and $381.1 \pm 29.3 \mathrm{~g}$, respectively. No significant difference was observed between the groups $(p>0.05)$.

\subsection{The Effect of B. longum on Blood Biochemical Assay and} Bone Mineral Content. The serum parameters are summarized in Table 2. The OVX rats without B. longum supplementation showed a significant reduction in serum osteocalcin (OC; $76.81 \pm 6.44 ; p<0.05)$ compared to the sham (184.61 $\pm 6.93 ; p<0.05)$ and B. longum-supplemented groups $(101.31 \pm 9.21 ; p<0.05)$. Ovariectomy increased serum level of CTX compared to the sham group $(249.28 \pm 7.57$ over $113.77 \pm 20.02 ; p<0.05$ ), which indicated an increased bone resorption activity. However, the $B$. longum-supplemented group showed a decrease in CTX serum level (147.05 \pm 6.25 ; $p<0.05)$ compared to the OVX group. Ca and Mg serum levels (Table 2) and the femur mineral content, including $\mathrm{Ca}$, $\mathrm{Mg}$, and $\mathrm{Zn}(\mathrm{mg} / \mathrm{g}$ ) (Table 3$)$, were not significantly affected by $B$. longum supplementation $(p>0.05)$.

3.3. B. longum Increased BMD and Changed the Trabecular Structure of the Femur. The reconstruction of $\mu$-CT scan images of the femur is illustrated in Figure 1. BMD $\left(\mathrm{g} / \mathrm{cm}^{3}\right)$, BV/TV (\%), total porosity (\%), Tb.N $\left(\mathrm{mm}^{-1}\right)$, Tb.Th (mm), 


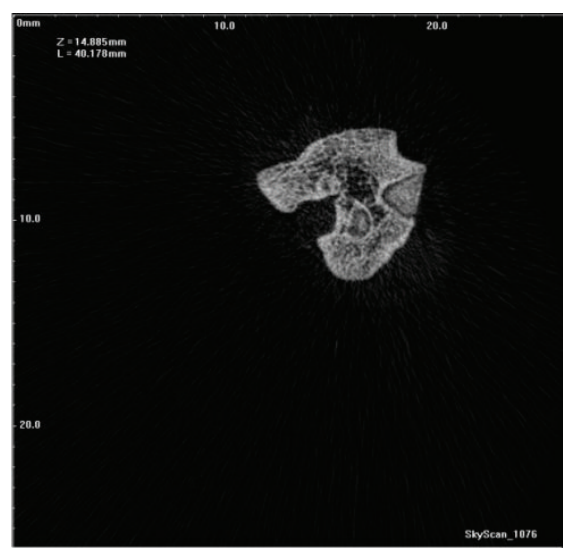

(a)

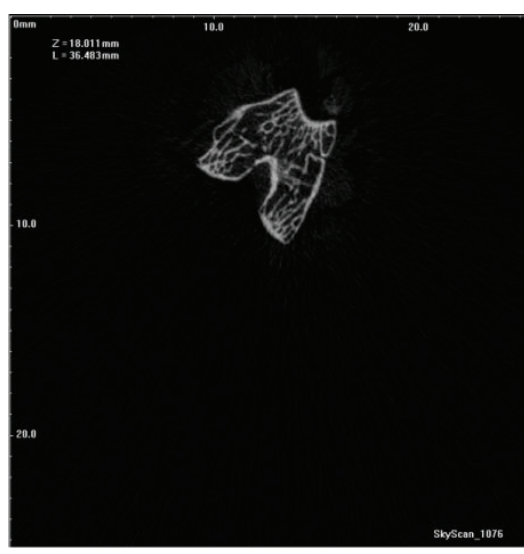

(b)

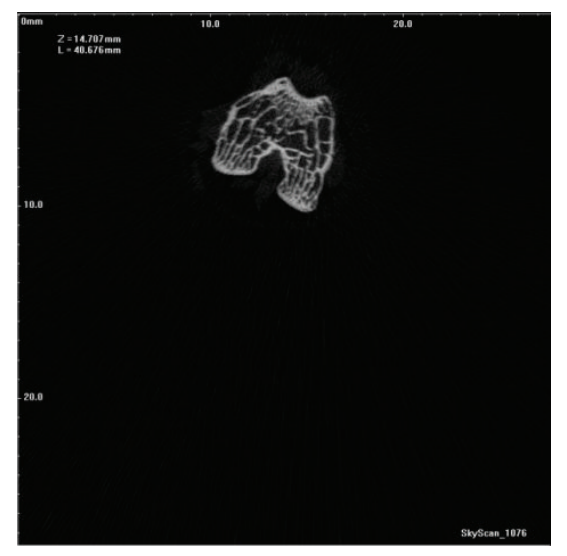

(c)

FIGURE 1: Reconstruction of $\mu$-CT scan image of the femur in the different groups. (a) Sham: sham-ovariectomized; (b) OVX: ovariectomized; (c) OVX $+1 \mathrm{~mL}$ of $10^{8}-10^{9} \mathrm{CFU}$ of B. longum.

TABLE 4: Effect of B. longum on the microstructure and BMD of the femur.

\begin{tabular}{lcccc}
\hline Parameters & Sham & OVX & OVX + B. longum & $p$ value \\
\hline BV/TV $(\%)$ & $73.66 \pm 6.45^{\mathrm{a}}$ & $49.60 \pm 5.69^{\mathrm{b}}$ & $60.55 \pm 3.57^{\mathrm{ab}}$ & 0.025 \\
Porosity (\%) & $24.84 \pm 5.45^{\mathrm{b}}$ & $44.25 \pm 3.98^{\mathrm{a}}$ & $34.85 \pm 2.25^{\mathrm{ab}}$ & 0.026 \\
Tb.Th $(\mathrm{mm})$ & $7.33 \pm 0.65^{\mathrm{a}}$ & $4.83 \pm 0.27^{\mathrm{b}}$ & $7.21 \pm 0.48^{\mathrm{a}}$ & 0.004 \\
Tb.Sp $(\mathrm{mm})$ & $5.48 \pm 0.42$ & $5.30 \pm 0.37$ & $6.03 \pm 0.16$ & 0.234 \\
Tb.N $\left(\mathrm{mm}^{-1}\right)$ & $0.12 \pm 0.01^{\mathrm{a}}$ & $0.10 \pm 0.01^{\mathrm{b}}$ & $0.09 \pm 0.01^{\mathrm{ab}}$ & 0.040 \\
BMD $\left(\mathrm{g} / \mathrm{cm}^{3}\right)$ & $1.06 \pm 0.02^{\mathrm{a}}$ & $0.59 \pm 0.07^{\mathrm{b}}$ & $0.89 \pm 0.06^{\mathrm{a}}$ & 0.013 \\
\hline
\end{tabular}

Ten-week-old female Sprague-Dawley rats were supplemented with $1 \mathrm{~mL}$ of $B$. longum $\left(10^{8}-10^{9} \mathrm{CFU}\right)$ once a day for 16 weeks, starting 2 weeks after surgery, while sham and OVX groups received $1 \mathrm{~mL}$ of demineralized water. At the end of the study, dissected femurs were analyzed with a micro-CT scan analyzer. Values represent the mean $\pm \operatorname{SEM}(n=8$ in each group).

BV/TV: bone volume/total volume; Tb.Th: trabecular thickness; Tb.Sp: trabecular separation; Tb.N: trabecular number; BMD: bone mass density.

${ }^{\mathrm{ab}}$ Values with different letters in the same row are significantly different at $p<0.05$ based on one-way ANOVA, followed by Tukey's post hoc test.

and Tb.Sp ( $\mathrm{mm})$ were measured using the $\mu$-CT analyzer and presented in Table 4 . OVX decreased the percentage of BV/TV $(49.60 \pm 5.69)$ and Tb.N $(0.10 \pm 0.01)(p<0.05)$ and increased the total porosity percentage $(44.25 \pm 3.98 ; p<$ 0.05). The B. longum supplementation increased the BV/TV\% and Tb.N and decreased total porosity \%, abolishing the effect of OVX. In addition, B. longum supplementation increased the Tb.Th close to that of the sham group. In this regard, OVX group showed the least Tb.Th as compared to the sham and $B$. longum-fed group $(4.83 \pm 0.27,7.33 \pm 0.657$, and $7.21 \pm 0.48$, resp.; $p<0.05)$. The present supplementation also increased the BMD of the femur compared to the OVX group $(0.89 \pm 0.06$ versus $0.59 \pm 0.07 ; p<0.05)$. There was no significant change in $\mathrm{Tb} . \mathrm{Sp}$ of the femur between groups.

\subsection{Effect of B. longum on the Femur Physical and Biome-} chanical Properties. The femur weight, height, and thickness did not differ significantly between the groups (Table 5). However, OVX reduced the strength of the femur $(0.54 \pm$ $0.09)$ as compared to that of the sham group $(0.90 \pm 0.12$; $p<0.05)$. The $B$. longum supplementation increased the strength of the femur $(0.63 \pm 0.07 ; p<0.05)$ (Figure 2).

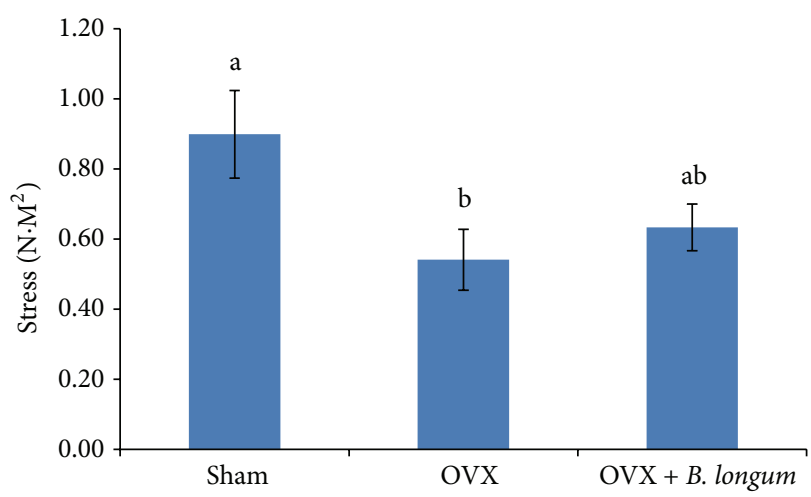

FIgURE 2: Effect of B. longum on the rat femur stress. Ten-week-old female Sprague-Dawley rats were supplemented with $1 \mathrm{~mL}$ B. longum $\left(10^{8}-10^{9} \mathrm{CFU}\right)$ once a day for 16 weeks, starting 2 weeks after surgery, while sham and OVX groups received $1 \mathrm{~mL}$ of demineralized water. At the end of the study, the femoral breaking force of dissected femurs was tested by using the three-point bending method in the center of the femur using a universal testing machine. Values represent the mean \pm SEM ( $n=8$ in each group). ${ }^{a b}$ Values with different letters in the same row are significantly different at $p<0.05$ based on one-way ANOVA, followed by Tukey's post hoc test. 
TABLE 5: Effect of B. longum on the physical properties of the femur.

\begin{tabular}{|c|c|c|c|c|}
\hline Femur physical characteristics & Sham & OVX & OVX + B. longum & $p$ value \\
\hline Weight $(\mathrm{g})$ & $1.06 \pm 0.03$ & $1.09 \pm 0.05$ & $1.10 \pm 0.04$ & 0.842 \\
\hline Height (mm) & $37.28 \pm 0.75$ & $37.36 \pm 0.41$ & $37.37 \pm 0.22$ & 0.989 \\
\hline Thickness (mm) & $4.05 \pm 0.16$ & $4.17 \pm 0.09$ & $4.17 \pm 0.07$ & 0.721 \\
\hline
\end{tabular}

Ten-week-old female Sprague-Dawley rats were supplemented with $1 \mathrm{~mL}$ of $B$. longum $\left(10^{8}-10^{9} \mathrm{CFU}\right)$ once a day for 16 weeks, starting 2 weeks after surgery, while sham and OVX groups received $1 \mathrm{~mL}$ of demineralized water. At the end of the study, the femur weight was measured by using a digital electronic scale and the height and thickness were measured using a stainless-steel caliper. Values represent the mean \pm SEM ( $n=8$ in each group).

No significant difference was observed between the groups based on one-way ANOVA, followed by Tukey's post hoc test.

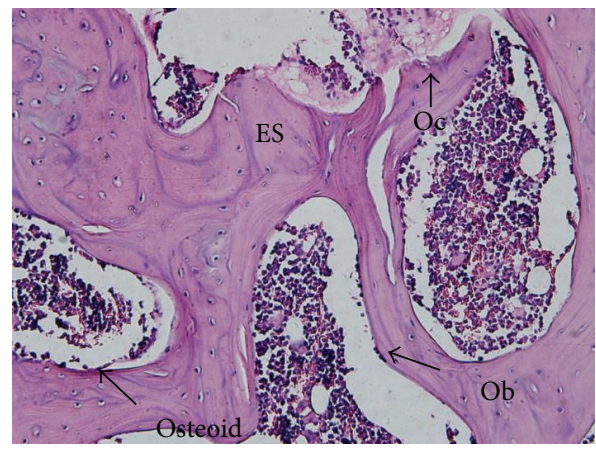

(a)

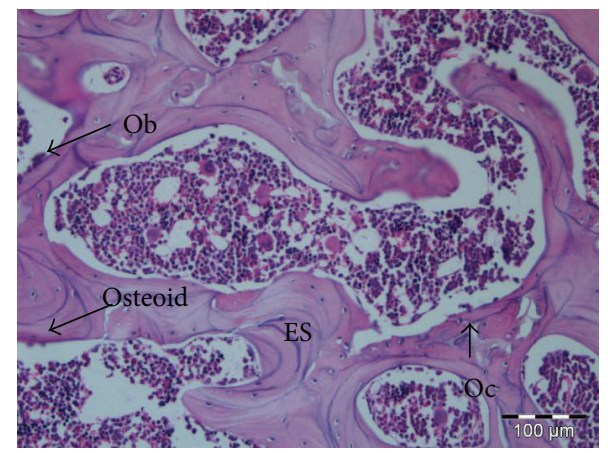

(b)

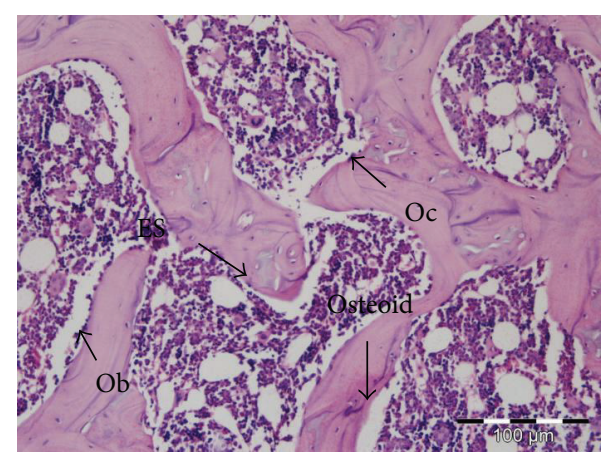

(c)

FIGURE 3: H\&E stained sections of the femur. (a) Sham: sham-ovariectomized; (b) OVX: ovariectomized; (c) OVX $+1 \mathrm{~mL}$ of $10^{8}-10^{9} \mathrm{CFU}$ of B. longum.

3.5. Effect of B. longum on Osteoblasts, Osteoclasts, Osteoid, and Eroded Surface over Bone Surface of the Femur. Osteoclasts, osteoblasts, and osteoid cells as well as eroded surface are shown in Figure 3. In addition, histomorphometric results, including $\mathrm{ObS} / \mathrm{BS}, \mathrm{OcS} / \mathrm{BS}, \mathrm{ES} / \mathrm{BS}, \mathrm{OS} / \mathrm{BS}$, and $\mathrm{OV} / \mathrm{BV}$, are summarized in Table 6. Compared to the sham group, OVX decreased ObS/BS (37.05 \pm 0.44$)$, OS/BS (18.08 $\pm 0.17)$, and OV/BV (7.06 \pm 0.30$)$ and increased OcS/BS (27.96 $\pm 0.33)$ and ES/BS $(37.78 \pm 0.30)(p<0.05)$. B. longum supplementation significantly increased the ObS/BS (46.85 \pm $1.42), \mathrm{OS} / \mathrm{BS}(23.06 \pm 1.19)$, and OV/BV $(10.15 \pm 1.19)$ and decreased OcS/BS $(25.54 \pm 1.23)$ and ES/BS $(34.24 \pm 1.25)$ when compared to the OVX group $(p<0.05)$.

3.6. Effect of B. longum on the Expression of Bone Morphometric Protein-2 (Bmp-2) and Secreted Protein Acidic and Rich in Cysteine (Sparc) Genes. Sparc and Bmp-2 gene expression is shown in Figures 4 and 5. Sparc and Bmp-2 were significantly downregulated in the OVX group $(p<0.05)$ and B. longum supplementation significantly upregulated the expression of Sparc $(1.67 \pm 0.16$ fold changes; $p<0.05)$ and Bmp-2 $(1.33 \pm$ 0.17 fold changes; $p<0.05)$ compared to that of the OVX group.

3.7. Enumeration of Bifidobacteria in Fecal Samples. The total bifidobacteria count in the feces is shown in Figure 6. $B$. longum supplementation significantly increased the number of the total bifidobacteria (CFU/g) in the feces of the supplemented group $(p<0.05)$.

\section{Discussion}

At the end of the study, all groups showed a similar body weight, as expected since the three diets used in this study 
TABLE 6: Effect of B. longum on histomorphometric measurements of the femur.

\begin{tabular}{lcccc}
\hline Parameters (\%) & Sham & OVX & OVX + B. longum & $p$ value \\
\hline ObS/BS & $53.30 \pm 2.29^{\mathrm{a}}$ & $37.05 \pm 0.44^{\mathrm{c}}$ & $46.85 \pm 1.42^{\mathrm{b}}$ & 0.046 \\
OcS/BS & $23.01 \pm 1.34^{\mathrm{c}}$ & $27.96 \pm 0.33^{\mathrm{a}}$ & $25.54 \pm 1.23^{\mathrm{b}}$ & 0.001 \\
OS/BS & $24.02 \pm 1.27^{\mathrm{a}}$ & $18.08 \pm 0.17^{\mathrm{c}}$ & $23.06 \pm 1.19^{\mathrm{b}}$ & 0.034 \\
OV/BV & $13.33 \pm 1.28^{\mathrm{a}}$ & $7.06 \pm 0.30^{\mathrm{c}}$ & $10.15 \pm 1.19^{\mathrm{b}}$ & 0.004 \\
ES/BS & $28.97 \pm 2.15^{\mathrm{c}}$ & $37.78 \pm 0.30^{\mathrm{a}}$ & $34.24 \pm 1.25^{\mathrm{b}}$ & 0.001 \\
\hline
\end{tabular}

Ten-week-old female Sprague-Dawley rats were supplemented with $1 \mathrm{~mL}$ B. longum $\left(10^{8}-10^{9} \mathrm{CFU}\right)$ once a day for 16 weeks, starting 2 weeks after surgery, while sham and OVX groups received $1 \mathrm{~mL}$ of demineralized water. At the end of the study, the percentage of osteoblast surface/bone surface (ObS/BS), osteoclast surface/bone surface (OcS/BS), eroded surface/bone surface (ES/BS), osteoid surface/bone surface (OS/BS), and osteoid volume/bone volume (OV/BV) was measured from H\&E stained sections of the dissected femur. Values represent the mean $\pm \operatorname{SEM}(n=8$ in each group).

${ }^{\mathrm{abc}}$ Values with different letters in the same row are significantly different at $p<0.05$ based on one-way ANOVA, followed by Tukey's post hoc test.

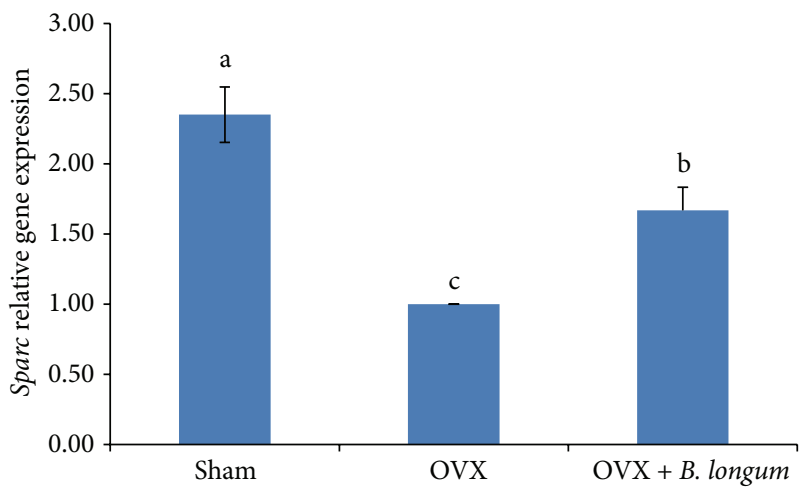

FIgURE 4: Effect of B. longum on Sparc gene expression. Tenweek-old female Sprague-Dawley rats were supplemented with $1 \mathrm{~mL}$ B. longum $\left(10^{8}-10^{9} \mathrm{CFU}\right)$ once a day for 16 weeks, starting 2 weeks after surgery, while sham and OVX groups received $1 \mathrm{~mL}$ of demineralized water. At the end of the study, Sparc expression was quantified by reverse transcription-polymerase chain reaction (RTPCR) analysis. Values represent the mean $\pm \operatorname{SEM}(n=8$ in each group). ${ }^{\text {abc }}$ Values with different letters are significantly different at $p<0.05$ based on one-way ANOVA, followed by Tukey's post hoc test.

were isocaloric and food consumption was similar in all groups. This result is in agreement with a previous study from Bryk et al. [28]. In this study, B. longum could increase the number of bifidobacteria in the feces of the rats and increased bone mass density, suggesting that the preventative effects of B. longum on osteoporosis might be due to its probiotic effects.

Osteoporosis is accompanied with low BMD and changes in microstructure of bone tissue such as reduction in $\mathrm{Tb}$.Th, Tb.N, and BV/TV\% and increase in Tb.Sp, total porosity, and risk of bone fracture. These characteristics of osteoporosis were observed in the OVX non-supplemented group in the present study. Similar results were reported in previous studies $[29,30]$. B. longum supplementation decreased Tb.Sp and total porosity of the femur and, in parallel, increased Tb.N, Tb.Th, and BV/TV and led to the improvement of the femur BMD. Indeed, trabecular microstructure and BV/TV are the main determinants of bone fracture and bone strength and have a positive relation with bone loss [31]. The reduction of bone strength decreased bone elasticity and loss of bone

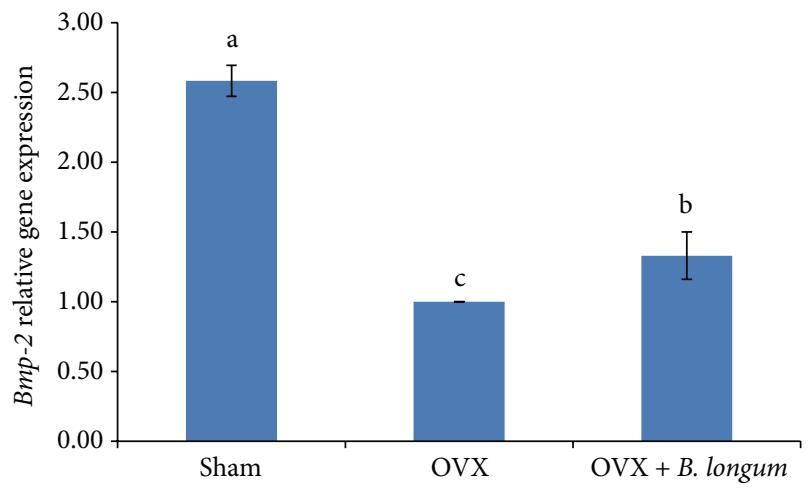

FIGURE 5: Effect of B. longum on Bmp-2 gene expression. Ten-weekold female Sprague-Dawley rats were supplemented with $1 \mathrm{~mL} B$. longum $\left(10^{8}-10^{9} \mathrm{CFU}\right)$ once a day for 16 weeks, starting 2 weeks after surgery, while the sham and OVX groups received $1 \mathrm{~mL}$ of demineralized water. At the end of the study, $B m p-2$ expression was quantified by RT-PCR. Values represent the mean \pm SEM $(n=8$ in each group). ${ }^{\text {abc }}$ Values with different letters are significantly different at $p<0.05$ based on one-way ANOVA, followed by Tukey's post hoc test.

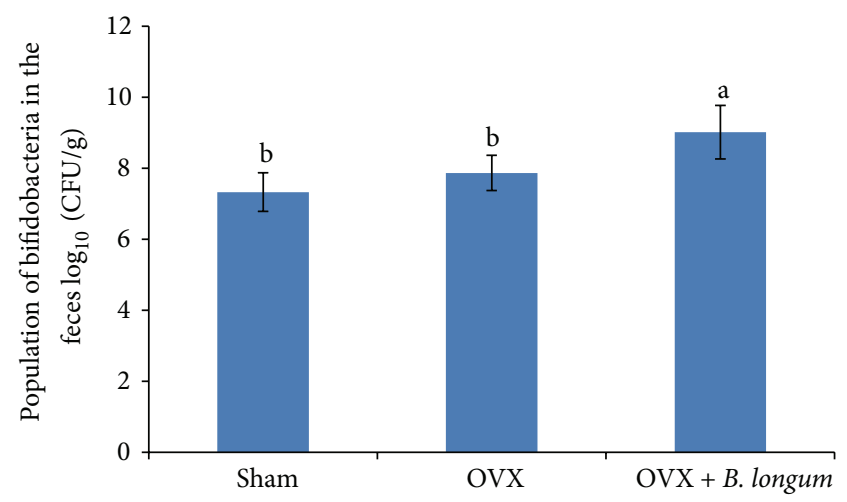

Figure 6: Effect of B. longum on the total population of bifidobacteria in the rat feces. Ten-week-old female Sprague-Dawley rats were supplemented with $1 \mathrm{~mL} \mathrm{~B}$. longum $\left(10^{8}-10^{9} \mathrm{CFU}\right)$ once a day for 16 weeks, starting 2 weeks after surgery, while the sham and OVX groups received $1 \mathrm{~mL}$ of demineralized water. At the end of the study, the amount of bifidobacteria was quantified in the feces. Values represent the mean \pm SEM ( $n=8$ in each group). ${ }^{\text {ab }}$ Values with different letters are significantly different at $p<0.05$ based on oneway ANOVA, followed by Tukey's post hoc test. 
elasticity is associated with bone fracture [32]. Thus, Tb.Th, Tb.N, and Tb.Sp as well as that of BV/TV are some of the predictors for bone fracture risk and osteoporosis, which were modulated by B. longum supplementation in this study. In fact, similar results regarding the changes of the trabecular microstructure by probiotics consumption were also reported by Chiang and Pan [7] and Shim et al. [33].

In the present study, $B$. longum reduced the bone resorption and increased bone formation as indicated by increasing $\mathrm{OC}$ and decreasing CTX levels in the serum and changes in the ratio of ObS/BS, OS/BS, OcS/BS, and $\mathrm{ES} / \mathrm{BS}$. A continuous bone remodeling process requires both osteoblasts and osteoclasts. Osteoclasts dissolve the bone matrix, which results in the occurrence of eroded surface [1], but the bone formation proceeds concurrently through the help of osteoblasts. Serum CTX is produced by osteoclasts during the bone resorption process and is a bone resorption marker, while serum OC is secreted only by osteoblast and osteocytes cells during the bone formation and is a bone formation marker [34]. Thus, the rise in the bone resorption process is accompanied with the rise of osteoclast activity and increased levels of CTX in the serum, while a rise in the bone formation process is accompanied with the increase of osteoblast activity and OC levels in the serum $[35,36]$. Therefore, the activity of osteoclasts and osteoblasts cells can be evaluated by measuring OC and CTX in the serum [37] and assessing the ratio of osteoblasts and osteoclast surface over bone surface. A rise in serum CTX and the ratio of OSc/BS and ES/BS in the trabecula, which occurred in the OVX rats, indicated that the bone resorption activity precedes the bone formation process. In the present study, $B$. longum supplementation decreased the ratio of OSc/BS and ES/BS and serum levels of CTX, while it increased the ratio of $\mathrm{ObS} / \mathrm{BS}, \mathrm{OS} / \mathrm{BS}$, and $\mathrm{OcS} / \mathrm{BS}$ and serum levels of $\mathrm{OC}$, indicating its beneficial health effect as a probiotic in preventing osteoporosis.

In addition, B. longum supplementation increased Bmp2 and Sparc expression. Bmp-2 is a growth factor and plays an essential role in skeletal development, especially in early embryogenesis [38], and is well known for bone formation signal [39] and appears as a key agent in the osteoblastic differentiation [40]. Besides, $B m p-2$ is a gene that controls both the proliferation and differentiation of osteoblasts [41]. The rise in Bmp-2 expression resulted in an increase in Bmp2 secretion in cells. Therefore, osteoblasts can regulate their own proliferation and differentiation, which is a key role during bone remodeling. On the other hand, $B m p-2$ can also help bone regeneration and repair and prevent apoptosis [42]. Bone regeneration is related to the elasticity of the bone and is associated with bone strength [43]. Therefore, the increasing femur strength by probiotic supplementation in the current study may also relate to the higher expression of Bmp-2. In this regard Kanakaris et al. [40] showed treatment of osteoporotic fracture with $B m p s$ induced rapid increase of bone strength in entire skeleton, especially at area of bone fracture. Another gene investigated in this study is Sparc, which encodes a noncollagenous protein in extracellular bone matrix necessary for collagen calcification in the bone [44]. Recent study investigated therapeutic effect of Sparc for treating or preventing bone related diseases. It is related to tissue remodeling, repair development, and bone mineralization [45]. Since Sparc participates in bone remodeling and is a Ca-binding receptor, and helps bone calcification [46], increasing its expression leads to increased bone calcification, resulting in stronger bones as observed in OVX rats supplemented with $B$. longum. Thus, Sparc upregulation can explain the increase in bone strength induced by B. longum supplementation.

An increased number of bifidobacteria in the feces of the rats demonstrated the increased colonization of the intestine and cecum by these bacteria and suggested the bacterial cell wall was intact after passage away through gastrointestinal tract (GI) and the bifidobacteria used in this study are resistant to acids and bile of the GI [47]; this helps the bacteria to survive through the passage of the GI in order to exert a better function [48]. Generally, probiotics have significant effects on the digestive tract by improving proliferation of intestinal epithelial cells due to the enhancement of short chain fatty acids (SCFA) production [49]. The production of SCFA decreases luminal $\mathrm{pH}$, subsequently increases mineral absorption [50] via their solubilization, and reduces secondary acid formation in the colon [17]. Thus, $\mathrm{Ca}$ absorption from the intestine increases due to the survival and functionality of probiotics in the GI. In this study, $B$. longum supplementation induced an increase in serum Ca levels, upregulated Sparc, and increased the Ca content of the femur as compared to the OVX non-supplemented group. Thereby, B. longum supplementation as a probiotic ameliorated bone loss induced by OVX. In addition, some studies showed chemotherapy in rats showed bone loss effects $[51,52]$, since our results showed that the Bifidobacterium longum could prevent the bone loss in the rat; thus it can be applicable for the rats under chemotherapy.

This research was not without its weaknesses. In this regard, there were some limitations that can be discussed. Firstly, this research only assessed BMD and BMC of the rats at the end of the study and compared between different groups. The study did not measure BMD and BMC of the rats before starting the treatments to compare changes of BMD and BMC of the femur before and after intervention. This limitation occurred due to the lack of available instrument before starting the intervention. Second, this research did not design the sham group supplemented with probiotic as a control for comparison. We just confine two groups as a control and one intervention group.

\section{Conclusion}

B. longum supplementation prevents bone loss induced by OVX in rats. Our findings illustrated that B. longum, as a probiotic supplement, increased bone formation, decreased bone resorption, and changed the microstructure of the femur. The femur BMD was increased due to the upregulation of Sparc and Bmp-2 genes. These data suggest that B. longum should be considered as a potential therapeutic agent to prevent postmenopausal osteoporosis. However, additional studies are required to explain the mechanism by which $B$. longum supplementation affects the outcomes described in this study. 


\section{Conflict of Interests}

The authors declare no conflict of interests regarding the publication of this paper.

\section{Acknowledgments}

The authors would like to thank the Biochemistry and Nutrition Laboratories from the Faculty of Medicine and Health Sciences, Universiti Putra Malaysia (UPM), and Tissue Engineering Centre of Universiti Kebangsaan Malaysia (UKM) for their help and assistance.

\section{References}

[1] S. Abdul-Majeed, N. Mohamed, and I.-N. Soelaiman, "Effects of tocotrienol and lovastatin combination on osteoblast and osteoclast activity in estrogen-deficient osteoporosis," EvidenceBased Complementary and Alternative Medicine, vol. 2012, Article ID 960742, 9 pages, 2012.

[2] R. T. Wilson, G. A. Chase, E. A. Chrischilles, and R. B. Wallace, "Hip fracture risk among community-dwelling elderly people in the United States: a prospective study of physical, cognitive, and socioeconomic indicators," American Journal of Public Health, vol. 96, no. 7, pp. 1210-1218, 2006.

[3] O. Johnell and J. A. Kanis, "An estimate of the worldwide prevalence and disability associated with osteoporotic fractures," Osteoporosis International, vol. 17, no. 12, pp. 1726-1733, 2006.

[4] P. Rahmani and S. Morin, "Prevention of osteoporosis-related fractures among postmenopausal women and older men," CMAJ, vol. 181, no. 11, pp. 815-820, 2009.

[5] E. B. Gold, "The timing of the age at which natural menopause occurs," Obstetrics \& Gynecology Clinics of North America, vol. 38, no. 3, pp. 425-440, 2011.

[6] C. Picherit, V. Coxam, C. Bennetau-Pelissero et al., "Daidzein is more efficient than genistein in preventing ovariectomyinduced bone loss in rats," Journal of Nutrition, vol. 130, no. 7, pp. 1675-1681, 2000.

[7] S.-S. Chiang and T.-M. Pan, "Antiosteoporotic effects of Lactobacillus-fermented soy skim milk on bone mineral density and the microstructure of femoral bone in ovariectomized mice," Journal of Agricultural and Food Chemistry, vol. 59, no. 14, pp. 7734-7742, 2011.

[8] F. C. Rodrigues, A. S. B. Castro, V. C. Rodrigues et al., "Yacon flour and bifidobacterium longum modulate bone health in rats," Journal of Medicinal Food, vol. 15, no. 7, pp. 664-670, 2012.

[9] G. S. Howarth and H. Wang, "Role of endogenous microbiota, probiotics and their biological products in human health," Nutrients, vol. 5, no. 1, pp. 58-81, 2013.

[10] S. N. Chilton, J. P. Burton, G. Reid, and G. Reid, "Inclusion of fermented foods in food guides around the world," Nutrients, vol. 7, no. 1, pp. 390-404, 2015.

[11] G. Reid, M. E. Sanders, H. R. Gaskins et al., "New scientific paradigms for probiotics and prebiotics," Journal of Clinical Gastroenterology, vol. 37, no. 2, pp. 105-118, 2003.

[12] C. Ohlsson, C. Engdahl, F. Fåk et al., "Probiotics protect mice from ovariectomy-induced cortical bone loss," PLoS ONE, vol. 9, no. 3, Article ID e92368, 2014.

[13] J. G. Kim, E. Lee, S. H. Kim, K. Y. Whang, S. Oh, and J.-Y. Imm, "Effects of a Lactobacillus casei 393 fermented milk product on bone metabolism in ovariectomised rats," International Dairy Journal, vol. 19, no. 11, pp. 690-695, 2009.

[14] K. Sjögren, C. Engdahl, P. Henning et al., "The gut microbiota regulates bone mass in mice," Journal of Bone and Mineral Research, vol. 27, no. 6, pp. 1357-1367, 2012.

[15] P. A. Bron, P. van Baarlen, and M. Kleerebezem, "Emerging molecular insights into the interaction between probiotics and the host intestinal mucosa," Nature Reviews Microbiology, vol. 10, no. 1, pp. 66-78, 2012.

[16] F. Yan and D. B. Polk, "Probiotics and immune health," Current Opinion in Gastroenterology, vol. 27, no. 6, pp. 496-501, 2011.

[17] K. Parvaneh, R. Jamaluddin, G. Karimi, and R. Erfani, "Effect of probiotics supplementation on bone mineral content and bone mass density," The Scientific World Journal, vol. 2014, Article ID 595962, 6 pages, 2014.

[18] C.-J. Rubin, J. Lindberg, C. Fitzsimmons et al., "Differential gene expression in femoral bone from red junglefowl and domestic chicken, differing for bone phenotypic traits," BMC Genomics, vol. 8, article 208, 2007.

[19] N. K. Arden, J. Baker, C. Hogg, K. Baan, and T. D. Spector, “The heritability of bone mineral density, ultrasound of the calcaneus and hip axis length: A study of postmenopausal twins," Journal of Bone and Mineral Research, vol. 11, no. 4, pp. 530-534, 1996.

[20] S. C. Manolagas, S. Kousteni, and R. L. Jilka, "Sex steroids and bone," Recent Progress in Hormone Research, vol. 57, Article ID 12017554, pp. 385-409, 2002.

[21] S. Kuroda, H. Mukohyama, H. Kondo et al., "Bone mineral density of the mandible in ovariectomized rats: analyses using dual energy X-ray absorptiometry and peripheral quantitative computed tomography," Oral Diseases, vol. 9, no. 1, pp. 24-28, 2003.

[22] S. I. Muhammad, M. Ismail, R. B. Mahmud, A. M. Salisu, and Z. A. Zakaria, "Germinated brown rice and its bioactives modulate the activity of uterine cells in oophorectomised rats as evidenced by gross cytohistological and immunohistochemical changes," BMC Complementary and Alternative Medicine, vol. 13, article 198, 2013.

[23] E. Harrison, A. Adjei, C. Ameho, S. Yamamoto, and S. Kono, "The effect of soybean protein on bone loss in a rat model of postmenopausal osteoporosis," Journal of Nutritional Science and Vitaminology, vol. 44, no. 2, pp. 257-268, 1998.

[24] T. Goda, K. Kishi, I. Ezawa, and S. Takase, "The maltitolinduced increase in intestinal calcium transport increases the calcium content and breaking force of femoral bone in weanling rats," Journal of Nutrition, vol. 128, no. 11, pp. 2028-2031, 1998.

[25] R. H. Freere and E. R. Weibel, "Stereologic techniques in microscopy," Journal of the Royal Microscopical Society, vol. 87, no. 1, pp. 25-34, 1967.

[26] P. A. J. Baldock, H. A. Morris, A. G. Need, R. J. Moore, and T. C. Durbridge, "Variation in the short-term changes in bone cell activity in three regions of the distal femur immediately following ovariectomy," Journal of Bone and Mineral Research, vol. 13, no. 9, pp. 1451-1457, 1998.

[27] W. W. Wilfinger, K. Mackey, and P. Chomczynski, "Effect of $\mathrm{pH}$ and ionic strength on the spectrophotometric assessment of nucleic acid purity," Biotechniques, vol. 22, pp. 474-476, 478481, 1997.

[28] G. Bryk, M. Z. Coronel, G. Pellegrini et al., "Effect of a combination GOS/FOS prebiotic mixture and interaction with calcium intake on mineral absorption and bone parameters in growing rats," European Journal of Nutrition, 2014. 
[29] S. Abdul-Majeed, N. Mohamed, and I.-N. Soelaiman, "The use of delta-tocotrienol and lovastatin for anti-osteoporotic therapy," Life Sciences, vol. 125, pp. 42-48, 2015.

[30] N. Muhammad, D. A. Luke, A. N. Shuid, N. Mohamed, and I.N. Soelaiman, "Two different isomers of vitamin e prevent bone loss in postmenopausal osteoporosis rat model," Evidence-Based Complementary and Alternative Medicine, vol. 2012, Article ID 161527, 7 pages, 2012.

[31] E. Legrand, D. Chappard, C. Pascaretti et al., "Trabecular bone microarchitecture, bone mineral density, and vertebral fractures in male osteoporosis," Journal of Bone and Mineral Research, vol. 15, no. 1, pp. 13-19, 2000.

[32] J. Wendlova, "Bone quality. Elasticity and strength," Bratislavské Lekárske Listy, vol. 109, no. 9, pp. 383-386, 2008.

[33] K.-S. Shim, T. Kim, H. Ha et al., "Lactobacillus fermentation enhances the inhibitory effect of Hwangryun-haedok-tang in an ovariectomy-induced bone loss," BMC Complementary and Alternative Medicine, vol. 13, article 106, 2013.

[34] P. Szulc and P. D. Delmas, "Biochemical markers of bone turnover: potential use in the investigation and management of postmenopausal osteoporosis," Osteoporosis International, vol. 19, no. 12, pp. 1683-1704, 2008.

[35] K. K. Ivaska, T. A. Hentunen, J. Vääräniemi, H. Ylipahkala, K. Pettersson, and H. K. Väänänen, "Release of intact and fragmented osteocalcin molecules from bone matrix during bone resorption in vitro," The Journal of Biological Chemistry, vol. 279, no. 18, pp. 18361-18369, 2004.

[36] H. N. Rosen, A. C. Moses, J. Garber et al., "Serum CTX: a new marker of bone resorption that shows treatment effect more often than other markers because of low coefficient of variability and large changes with bisphosphonate therapy," Calcified Tissue International, vol. 66, no. 2, pp. 100-103, 2000.

[37] C. M. B. Barco, S. M. Arija, and M. R. Pérez, "Biochemical markers in osteoporosis: usefulness in clinical practice," Reumatologia Clinica, vol. 8, no. 3, pp. 149-152, 2012.

[38] U. Styrkarsdottir, J.-B. Cazier, A. Kong et al., "Linkage of osteoporosis to chromosome 20p12 and association to BMP2," PLoS Biology, vol. 1, no. 3, article e69, 2003.

[39] V. Rosen, "BMP2 signaling in bone development and repair," Cytokine and Growth Factor Reviews, vol. 20, no. 5-6, pp. 475480, 2009.

[40] N. K. Kanakaris, G. Petsatodis, M. Tagil, and P. V. Giannoudis, "Is there a role for bone morphogenetic proteins in osteoporotic fractures?” Injury, vol. 40, supplement 3, pp. S21-S26, 2009.

[41] I. Garrett, D. Chen, G. Gutierrez et al., "Selective inhibitors of the osteoblast proteasome stimulate bone formation in vivo and in vitro," The Journal of Clinical Investigation, vol. 111, no. 11, pp. 1771-1782, 2003.

[42] Y. Guo, L. Ren, C. Liu et al., "Effect of implantation of biodegradable magnesium alloy on BMP-2 expression in bone of ovariectomized osteoporosis rats," Materials Science and Engineering: C, vol. 33, no. 7, pp. 4470-4474, 2013.

[43] F. Barrère, C. A. van Blitterswijk, and K. de Groot, "Bone regeneration: molecular and cellular interactions with calcium phosphate ceramics," International Journal of Nanomedicine, vol. 1, no. 3, pp. 317-332, 2006.

[44] F. Kuwata, K. L. Yao, J. Sodek, S. Ives, and D. Pulleyblank, "Identification of pre-osteonectin produced by cell-free translation of fetal porcine calvarial mRNA," The Journal of Biological Chemistry, vol. 260, no. 11, pp. 6993-6998, 1985.
[45] N. Ribeiro, S. R. Sousa, R. A. Brekken, and F. J. Monteiro, "Role of sparc in bone remodeling and cancer-related bone metastasis," Journal of Cellular Biochemistry, vol. 115, no. 1, pp. 17-26, 2014.

[46] M.-H. Huynh, E. H. Sage, and M. Ringuette, "A calciumbinding motif in SPARC/osteonectin inhibits chordomesoderm cell migration during Xenopus laevis gastrulation: evidence of counter-adhesive activity in vivo," Development, Growth \& Differentiation, vol. 41, no. 4, pp. 407-418, 1999.

[47] A. Hosono, "Viability of Lactobacillus gasseri and its cholesterolbinding and antimutagenic activities during subsequent refrigerated storage in nonfermented milk," Journal of Dairy Science, vol. 82, no. 12, pp. 2536-2542, 1999.

[48] E. Bertazzoni Minelli, A. Benini, M. Marzotto et al., "Assessment of novel probiotic Lactobacillus casei strains for the production of functional dairy foods," International Dairy Journal, vol. 14, no. 8, pp. 723-736, 2004.

[49] T. Sakata, T. Kojima, M. Fujieda, M. Miyakozawa, M. Takahashi, and K. Ushida, "Probiotic preparations dose-dependently increase net production rates of organic acids and decrease that of ammonia by pig cecal bacteria in batch culture," Digestive Diseases and Sciences, vol. 44, no. 7, pp. 1485-1493, 1999.

[50] S. Moslehi-Jenabian, L. L. Pedersen, and L. Jespersen, "Beneficial effects of probiotic and food borne yeasts on human health," Nutrients, vol. 2, no. 4, pp. 449-473, 2010.

[51] T. Shandala, Y. Shen Ng, B. Hopwood, Y.-C. Yip, B. K. Foster, and C. J. Xian, "The role of osteocyte apoptosis in cancer chemotherapy-induced bone loss," Journal of Cellular Physiology, vol. 227, no. 7, pp. 2889-2897, 2012.

[52] T. Shandala, Y. S. Ng, B. Hopwood, Y.-C. Yip, B. K. Foster, and C. J. Xian, "The role of osteocyte apoptosis in cancer chemotherapy-induced bone loss," Journal of Cellular Physiology, vol. 227, no. 7, pp. 2889-2897, 2012. 


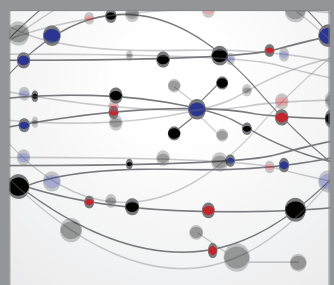

The Scientific World Journal
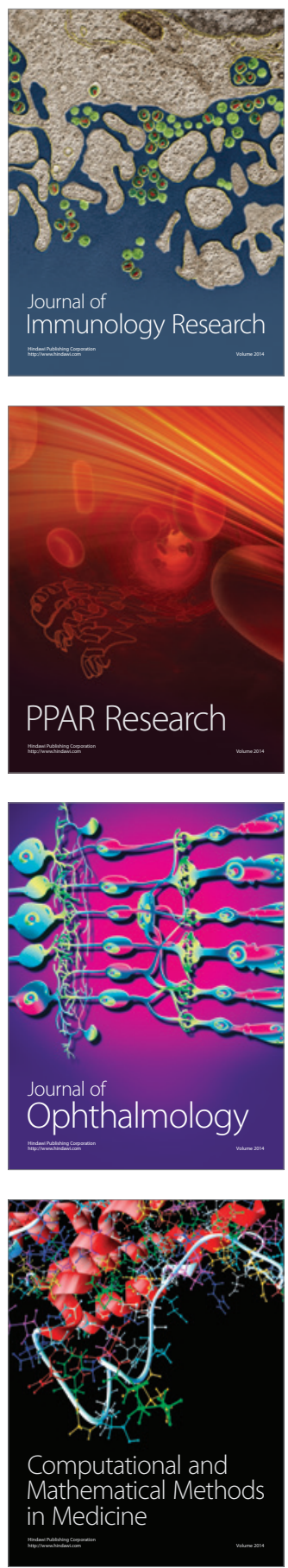

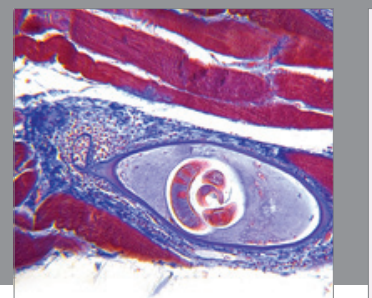

Gastroenterology

Research and Practice
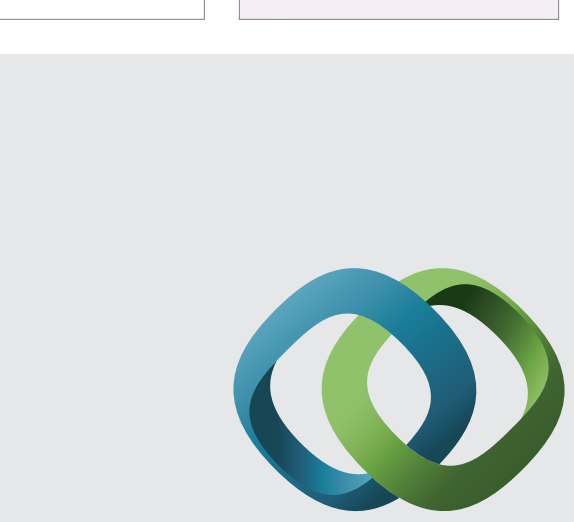

\section{Hindawi}

Submit your manuscripts at

http://www.hindawi.com
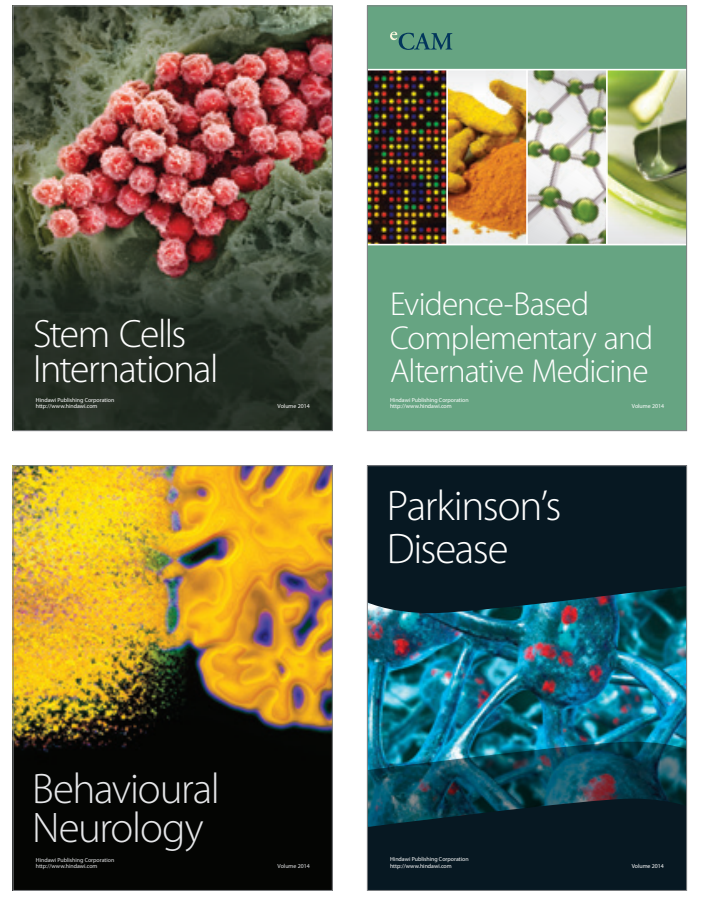
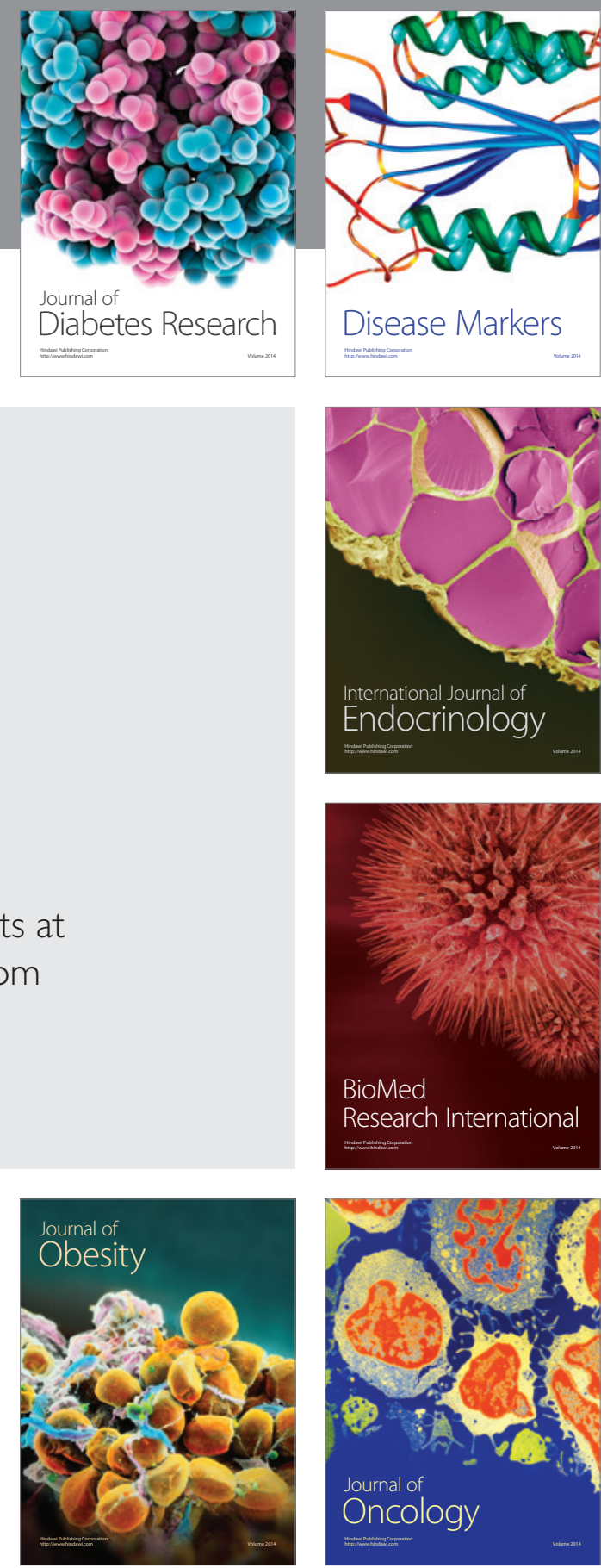

Disease Markers
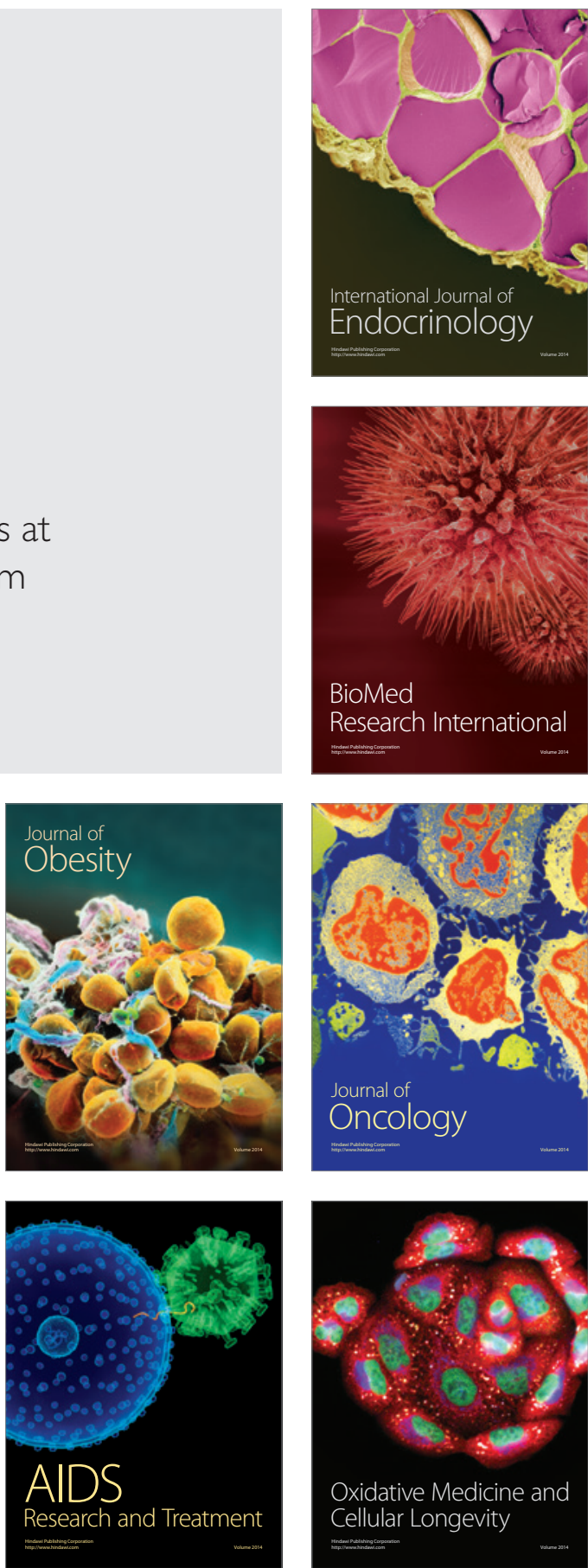